\title{
Production and Marketing System of Khasi Mandarin in Eastern Himalayas: An Economic Study from Assam
}

\author{
Rajiv Kumar Rana ${ }^{1}$ and Sanjeev Kumar ${ }^{2 *}$ \\ ${ }^{1}$ Dept. of Agricultural Economics and Farm Management, Assam Agricultural University, Jorhat, Assam-785013, India \\ ${ }^{2}$ Dept. of Social Sciences, Dr. YS Parmar University of Horticulture \& Forestry, Nauni, Solan, Himachal Pradesh-173230, India \\ *Corresponding author: sharmask93@rediffmail.com
}

\begin{abstract}
The present study was conducted to analyze the production and marketing system of Khasi Mandarin in Eastern Himalayas of India. The data was collected through pre-tested schedule by personally interviewing the farmers selected through multistage sampling technique. The objectives were studied using analytical tools like semi log exponential function, marketing cost, marketing margin, price spread and marketing efficiency analysis using Acharya's and Shepherd's approach The results of the study revealed that the compound growth rate of area $(-1.42 \%)$ and production $(-0.36 \%)$ of Khasi mandarin was negative and had badly affected the Khasi mandarin cultivation in the study area. However, the positive growth rate of productivity $(1.08 \%)$ was responsible for maintenance of production at a decent level. The marketing efficiency estimated by using both Acharya's approach and Shepherd's approach was found highest in Channel- I (Producer - Retailer - Consumer) followed by channel-II (Producer - Merchant wholesalersRetailers - Consumers) and channel -III (Producer - Pre-harvest contractors - Wholesalers - Retailers - Consumers), respectively. The producer's share in consumer's rupee was also maximum in channel-I (50.43\%) followed by channel-II (36.55\%) and channel-III $(20.38 \%)$. It was found that price spread was maximum in channel III (₹ 5080.00) followed by channel II (₹ 3820.00) and channel I (₹ 2537.50).
\end{abstract}

Keywords: Khasi mandarin, marketing channels, multistage sampling, price spread

Citrus are among the most important fruit trees in the world horticulture scenario. The cultivation of citrus dates back to pre-historic times. The Mandarin, the Citron and the Pomelo are the ancestors of the most other commercial citrus varieties. Globally, citrus is cultivated in 114 countries and among these, 53 countries grow citrus commercially with a total production of more than 115 million tonnes. After Mexico, India is the leading producer of citrus fruits with an area of about 1.06 million hectares and production of about 12.75 million tonnes annually. In the world, citrus is dominated by sweet orange with a $64 \%$ contribution followed by mandarins with $20 \%$, limes and lemons with $10 \%$ and rest of the $6 \%$ contributed by grapefruit and other citrus fruits (Anonymous, 2016).

Mandarin orange is considered to be originated from South Eastern Asia and the Philippines.
Mandarins are grown in the tropical/sub-tropical region $35^{\circ} \mathrm{N}$ to $35^{\circ} \mathrm{S}$ of equator. Brazil, China, Egypt, Japan, India, Iran, Italy, Mexico, Spain, Thailand, Turkey, and USA are the main Mandarin producing countries. During 2009, the total acreage under the Mandarin was 2159.17 thousand hectares. The area under Mandarin in China was maximum i.e., 1374.16 thousand hectares $(63.64 \%)$, followed by Spain 122 thousand hectares (5.65\%). The area under Mandarin in Italy was 38.300 thousand hectares $(1.77 \%)$ and in Argentina, it was 32 thousand hectares (1.48\%) (Anonymous, 2016).

In India, the total mandarin production is 4754 thousand tonne on 429 thousand ha area with $11.08 \mathrm{t}$ /ha productivity (Anonymous, 2016-17b). In India, Punjab is the highest producer of Mandarin with a production of 1140.31 thousand tonne on 49.36 thousand ha area, followed by Maharashtra, 
Madhya Pradesh, Rajasthan and Assam at $2^{\text {nd }}, 3^{\text {rd }}$, $4^{\text {th }}$ and $5^{\text {th }}$ place respectively in order of appearance. In terms of area under mandarin Maharashtra ranks first with 107.7 thousand ha area followed by Madhya Pradesh at $2^{\text {nd }}$ place with 69.7 thousand ha area, Punjab at third with 49.36 thousand ha. Similarly, Arunachal Pradesh with 42.64 thousand ha area and Assam with 17.43 thousand ha ranks at fourth and fifth place, respectively. It is interesting to note here that five North Eastern states namely Arunachal Pradesh, Assam, Manipur, Meghalaya and Mizoram are featured in the top ten producer of mandarin in India.

The North Eastern Region of India is most vital, when we consider citrus fruit (Ghosh 1977; Ray and Deka 2000) especially mandarin orange (Singh and Chadha1993; Hazarika 2012) because almost all of the states in the region have reasonable presence of mandarin in terms of area as well as production. But, what is more noteworthy here is the presence of enormous amount of genetic resources that can lead to greater economic and scientific significance. This can be easily shown by the products which have already received the GI tag, such as Khasi Mandarin (Meghalaya), Kachai lemon (Manipur) and Arunachal orange. North Eastern Region as a whole accounts for 674.19 thousand tonne of mandarin production and 116.57 thousand hectare of area under mandarin which translates into 18.7 per cent of total mandarin production in the country and $30.66 \%$ of total area under mandarin in India (Anonymous, 2015). Assam and Arunachal Pradesh, both combined have 441.93 thousand MT of Mandarin produce accounting to a staggering $65.55 \%$ of total mandarin production of North Eastern Region. Similarly, in case of area, both combined have 60.07 million hectare accounting to $51.53 \%$ of total area under mandarin in NER (Anonympus 2016-17a).

Assam occupies an area of 42.64 thousand hectares under mandarin with production of 217.04 thousand tonne. The leading district in terms of area and production of mandarin is Dima hasao with 57359 MT of production on 4225 hectare of land followed by Kamrup(R), Tinsukia, Karbi-Anglong, and Kamrup (M) respectively in terms of production. In terms of productivity, Tinsukia comes first with $20110 \mathrm{Kg} /$ ha followed by Karbi-Anglong $(17285 \mathrm{Kg}$ ) ha), Dima Hasao (13576 Kg/ha), Dibrugarh (12885
$\mathrm{Kg} / \mathrm{ha}$ ) and Jorhat (12835 Kg/ha) (Anonympus 201617a). Tinsukia district of Assam occupies $11.77 \%$ of the total mandarin area in the state and produces $7.42 \%$ of the total mandarin produce of the state Major areas of orange orchards in Tinsukia district are Ketekong, Margherita, Talap, Kakopathar, Hapjan, Doomdooma, Philobari etc. (Mahanta and Konwar, 2014). Apart from production; Tinsukia also plays an important role in marketing of mandarin as it is one of the important hubs of marketing of mandarin in the region. Tinsukia market acts as a connection between main market of Guwahati, Kolkata, Cachar, Karimganj and center of export to other countries like Bhutan, Burma and Bangladesh. Therefore, the present study has been undertaken to study the production status of Khasi Mandarin and identify the existing marketing channels and assess the marketing costs, margins, price spread and marketing efficiency of different marketing channels involved in the marketing of Khasi mandarin in the study area.

\section{DATA BASE AND METHODOLOGY}

The present study was conducted during agricultural year 2016-17 in the Tinsukia district of Assam purposively because of its highest productivity and diverse marketing of Khasi mandarin in the state. The multistage sampling technique was used to select the ultimate sample of 100 Khasi mandarin growers. In the first stage of sampling, three ADO circle namely Hapjan, Kakopathar and Margherita were purposively selected for having a major production and area under Mandarin orange plantation of the district. In the second stage, three villages were selected from Kakopathar, Margherita ADO circle and four villages were selected from Hapjan ADO circle on the basis of highest area and production under Mandarin orange cultivation and then, at the third stage of sampling, from each selected village, ten mandarin orange growers were selected randomly. Further, the farm families were classified on the basis of their area under mandarin orange plantation into three categories i.e. Marginal (up to $1 \mathrm{ha}$ ), Small (1.01 ha to 2 ha) and Medium (2.01 to 4 ha). Thus, the total sample size of 100 growers was comprised of 75 marginal growers, 17 small growers and 7 medium growers. The data regarding marketing of mandarin were collected through survey method by interviewing 
the growers and marketing intermediaries directly through a pretested schedule. The secondary data pertaining to the area, production and productivity of mandarin orange were collected from the Directorate of Economics and Statistics, Guwahati (Assam). The following analytical tools were used in the present study:

\section{Compound Growth Rate analysis}

The compound annual growth rates (CAGR) of area, production and productivity for Khasi mandarin in the study area were estimated by using the semi log exponential function of the following form on the time series data from 2003-04 to 2014-15;

$$
\log Y_{t}=a+b^{t}
$$

This equation (1) can be elaborated in details as:

$$
Y_{t}=Y_{o}(1+r)^{t}
$$

Taking $\log$ on both sides, we get,

$$
\log Y_{t}=\log Y_{o}+t \log (1+r)
$$

Equation (ii) can be rewrite as,

$$
Y=a+b t
$$

In the above equation, $Y$ represents $\log Y_{t^{\prime}} a$ represents $\log Y_{o}$ and $b$ represents $\log (1+r)$. Where;

$Y=$ area/production/ productivity,

$a=$ constant

$t=$ Time variable in year $(1,2 \ldots n)$

$b=$ Regression Coefficient that shows the rate of change or growth rates in a series

The annual compound growth rate (s) was worked out by using:

Antilog $(b)=$ Antilog $(\log (1+r))$.

Antilog $(b)=1+r$ and

$r=$ Antilog $b-1$

When multiplied by 100, it gave the percentage growth rate in area, production and productivity.

\section{Measures of dispersion: Coefficient of Variation}

A coefficient of variation $(\mathrm{CV})$ is a statistical measure of the dispersion of data points in a data series around the mean. The coefficient of variation represents the ratio of the standard deviation to the mean, and it is a useful statistic for comparing the degree of variation from one data series to another, even if the means are drastically different from one another. It was calculated to observe the dispersion of area, production and productivity parameters of Khasi mandarin in the study area over the 12 year period by using following formula:

$$
c v=\left(\frac{\sigma}{\mu}\right) \times 100
$$

Where, $\sigma$ is sample standard deviation and $\mu$ represents sample mean.

\section{Marketing analysis}

\section{Marketing cost}

The total marketing cost (TMC) incurred by the producer/seller and by various intermediaries was calculated as:

$$
\mathrm{TMC}=C_{p}+\Sigma M C_{i}
$$

Where,

TMC is the total marketing cost

$C_{p}$ is the marketing cost incurred by farmer $M C_{i}$ is the marketing cost incurred by $\mathrm{i}^{\text {th }}$ trader or intermediary

\section{Marketing margin}

Marketing margin of middlemen was calculated as the difference between the total payment (marketing cost + purchase price) and receipts (sale price) of the middlemen and was calculated as:

$$
A m i=P_{S}-\left(P_{P}+M C_{i}\right)
$$

Where,

Ami is the absolute marketing margin of $i^{\text {th }}$ middlemen

$P_{S}$ is the selling price of the $i^{\text {th }}$ middlemen

$P_{P}$ is the purchase price of the $i^{\text {th }}$ middlemen

$M C_{i}$ is the marketing cost incurred by $i^{\text {th }}$ intermediary

\section{Price spread}

Price spread is defined as the difference between the retail price and the farm gate price.

Price spread $=P_{C}-P_{F}$ 
Where,

$P_{C}$ is the price paid ultimately by the consumer

$P_{F}$ is the price received by the farmer

Producer's share in consumer's rupee is calculated by the formulae:

\section{Producer's share in consumer's rupee}

It was calculated by using following formula:

Producer's share in consumer's rupee $=\left(P_{F} / P_{C}\right)^{*} 100$

Where;

$P_{F}$ is the price received by the farmer

$P_{C}$ is the price paid by the consumer

\section{Marketing efficiency analysis}

The marketing efficiency of the selected channels was studied by using two formulas namely Modified Acharya's formula and Shepherd's formula.

Modified Acharya's formula is given as:

$$
M M E=\frac{\mathrm{P}_{\mathrm{f}}}{(\mathrm{TMC}+\mathrm{TMM})}
$$

Where,

$M M E$ is modified measure of marketing efficiency (Acharya's formula)

$P_{f}$ is price received by farmer

TMC is Total marketing cost incurred in a particular marketing channel

TMM is Total marketing margin of all intermediaries

Shepherd's approach of marketing efficiency is given as:

$$
M E=P_{C} /\left(M C_{P}+T M C+T M M\right)
$$

Where,

ME is Marketing efficiency (Shepherd's formula)

$P_{C}$ is Consumer's purchase price

$M C_{P}$ is Marketing cost incurred by producer

TMC is Total marketing cost incurred in a particular marketing channel

TMM is Total marketing margin of all intermediaries

\section{RESULTS AND DISCUSSION}

\section{Growth and Instability Analysis}

The data in the Table 1 showed the area, production and productivity of Khasi mandarin orange in Tinsukia district for a period of twelve years starting from 2003-04 to 2014-15. The data revealed that from 2003-04 to 2014-15, the area under Khasi mandarin in the selected district has been decreased from 1335 ha to 1197 ha. The CAGR for the area was -1.42 and significant which revealed that the general decline in area was high in comparison to increase in area in few years leading to negative growth rate. The data related to production showed a non- significant negative growth trend over the period of twelve years with -0.36 CAGR. The results related to productivity showed a significant positive growth rate with CAGR value of 1.08 The coefficient of variation $(\mathrm{CV})$ clearly showed that the production had the highest $C V$ value (8.68) due to the high variation in production followed by area (8.05) and productivity (7.24).

Table 1: Growth \& Instability analysis of area, production \& productivity of Khasi mandarin orange in Tinsukia from 2003-04 to 2014-15

\begin{tabular}{cccc}
\hline Year & Area (ha) & Production (t) & $\begin{array}{c}\text { Productivity } \\
\text { (kg/ha) }\end{array}$ \\
\hline $2003-04$ & 1335 & 21343 & 15987 \\
$2004-05$ & 1320 & 21142 & 16016 \\
$2005-06$ & 1320 & 21150 & 16022 \\
$2006-07$ & 1320 & 21132 & 16009 \\
$2007-08$ & 1370 & 21924 & 16003 \\
$2008-09$ & 1455 & 23300 & 16013 \\
$2009-10$ & 1100 & 17611 & 16009 \\
$2010-11$ & 1205 & 19291 & 16009 \\
$2011-12$ & 1189 & 18710 & 15736 \\
$2012-13$ & 1191 & 19860 & 16675 \\
$2013-14$ & 1197 & 19960 & 16675 \\
$2014-15$ & 1185 & 23829 & 20110 \\
CAGR (\%) & $-1.42^{*}$ & -0.36 & $1.08^{*}$ \\
CV & 8.05 & 8.68 & 7.24 \\
\hline
\end{tabular}

Note: * significant at $1 \%$.

Source: Anonympus, 2016-17a.

\section{Category wise marketable surplus and other production characteristics}

The results in the Table 2 showed the category wise production, productivity, consumption and 
Table 2: Category-wise productivity, production, consumption and marketed surplus of the sample area

\begin{tabular}{cccccc}
\hline Category & $\begin{array}{c}\text { Average size of operational } \\
\text { land holding (ha) }\end{array}$ & $\begin{array}{c}\text { Productivity } \\
\text { (no. of fruits/ha) }\end{array}$ & $\begin{array}{c}\text { Production } \\
\text { (no. of fruits) }\end{array}$ & $\begin{array}{c}\text { Consumption and } \\
\text { other uses } \\
\text { (no. of fruits) }\end{array}$ & $\begin{array}{c}\text { Marketed Surplus } \\
\text { (no. of fruits) }\end{array}$ \\
\hline Marginal & 0.46 & 123713 & 57403 & 2599 & 54804 \\
Small & 1.53 & 103550 & 157913 & 4555 & 153358 \\
Medium & 2.97 & 262417 & 778854 & 6429 & 772425 \\
All Farms & 0.83 & 151775 & 125972 & 3217 & 122755 \\
\hline
\end{tabular}

Source: Primary Survey.

other uses with marketable surplus under each category. The production, consumption and marketed surplus were determined based on the average size of operational land holding under each category whereas productivity was calculated number of fruits per hectare basis. The table clearly showed that medium category farms had the highest productivity, production, consumption and marketed surplus. It was found that on the productivity front medium farms lead with yield of 262417 number of fruits per hectare followed by marginal farms (123713 No. of fruits/ha) and small farms (103550 No. of fruits/ha) with overall productivity of all farms equal to 151775 number of fruits per hectare.

In case of production, the production of medium farms (778854 No. of fruits) was highest followed by small farms (157913 No. of fruits) and marginal farms (57403 No. of fruits). The average production for all farms was 125972 numbers of fruits. Quantity of produce retained for home consumption and other purposes was 2599 number of fruits on marginal farms, 4555 number of fruits on small farms and 6429 number of fruits on medium farms Overall, for all farms, quantity retained for home consumption and other uses is 3217 number of fruits. On an average, marketed surplus of medium farmers (772425 No. of fruits) was highest followed by small farmers (153358 No. of fruits) and marginal farmers (54804 No. of fruits). The marketed surplus for all farms was 122755 number of fruits.

\section{Marketing channels}

The main marketing channels identified and the percentage of commodity transacted through each of these channels in the study area which were involved in the marketing of Khasi mandarin are presented in Table 3. The results in table showed that Channel IV has the highest percentage commodity transaction of $42.25 \%$ followed by Channel II (25.87\%), Channel III $(19.56 \%)$ and Channel I $(12.32 \%)$. Channel I, II, III were selected for further investigation due to ease in locating and following the commodity through these channels. Whereas, in case of channel IV the further investigation becomes difficult due to the involvement of distant intermediaries and far off market making it difficult for the researcher to follow the commodity and get essential details accurately.

Table 3: Marketing channels identified for mandarin and channel wise transaction of mandarin

\begin{tabular}{ccc}
\hline Particulars Marketing Channels & $\begin{array}{c}\text { Percentage of } \\
\text { commodity } \\
\text { transacted (\%) }\end{array}$ \\
\hline Channel I & $\begin{array}{l}\text { Producer - Retailers - } \\
\text { Consumers }\end{array}$ & 12.32 \\
Channel II & $\begin{array}{l}\text { Producer - Merchant } \\
\text { wholesalers - Retailers - } \\
\text { Consumers }\end{array}$ & 25.87 \\
Channel III & Producer - Preharvest \\
& contractors - Wholesalers \\
- Retailers - Consumers & 19.56 \\
Channel IV Producer - Pre harvest \\
contractors - Distant \\
wholesalers - Distant \\
retailers - Consumers
\end{tabular}

Source: Primary Survey.

\section{Marketing cost}

The data in the Table 4 depicted the marketing cost incurred by various market functionaries under each marketing channel. The total marketing cost in channel I was ₹ 527.5 per thousand fruits, out of the total marketing cost the marketing cost incurred by producer was ₹ 312.50 per thousand fruits which is $59.24 \%$ of total marketing cost in channel I. Similarly, the marketing cost incurred by the retailer was ₹ 215.00 per thousand fruits which 
Table 4: Marketing costs incurred by market functionaries in different channels (Rupees per thousand fruits)

\begin{tabular}{ccccc}
\hline \multicolumn{1}{c}{ S1. No. } & Name of the functionary/ Items of Cost & Channel I & Channel II & Channel III \\
\hline A. & Marketing Cost incurred by Producer & & - & - \\
\hline 1 & Plucking charges & 200.00 & - & - \\
2 & Cleaning and Grading & 0.00 & - & - \\
3 & Transportation Cost & 62.50 & - & - \\
4 & Market Fee & 20.00 & & - \\
5 & Misc. & 30.00 & & \\
\cline { 2 - 5 }
\end{tabular}

\begin{tabular}{ccccc}
\hline B. & Marketing Cost incurred by Merchant wholesaler & & \\
\hline 1 & Transportation Cost & - & 112.50 & - \\
2 & Plucking charge & - & 200.00 & - \\
3 & Loading and Unloading & - & 50.00 & - \\
4 & Market fee & - & 20.00 & - \\
5 & Physical Damage and Spoilage & - & 75.00 & - \\
6 & Misc. & & 50.00 & - \\
\cline { 2 - 6 }
\end{tabular}

\begin{tabular}{ccccc}
\hline C. & Marketing Cost incurred by Pre-harvest Contractors & & \\
\hline 1 & Transportation Cost & - & - & 95.00 \\
2 & Plucking Charges & - & - & 200.00 \\
3 & Loading \& Unloading & - & - & 35.00 \\
4 & Market Fee & - & - & 30.00 \\
5 & Physical loss and Spoilage & - & - & 45.00 \\
6 & Misc. & & 40.00 \\
\cline { 2 - 5 } & Total & & $\mathbf{4 4 5 . 0 0}(\mathbf{5 7 . 0 5})$
\end{tabular}

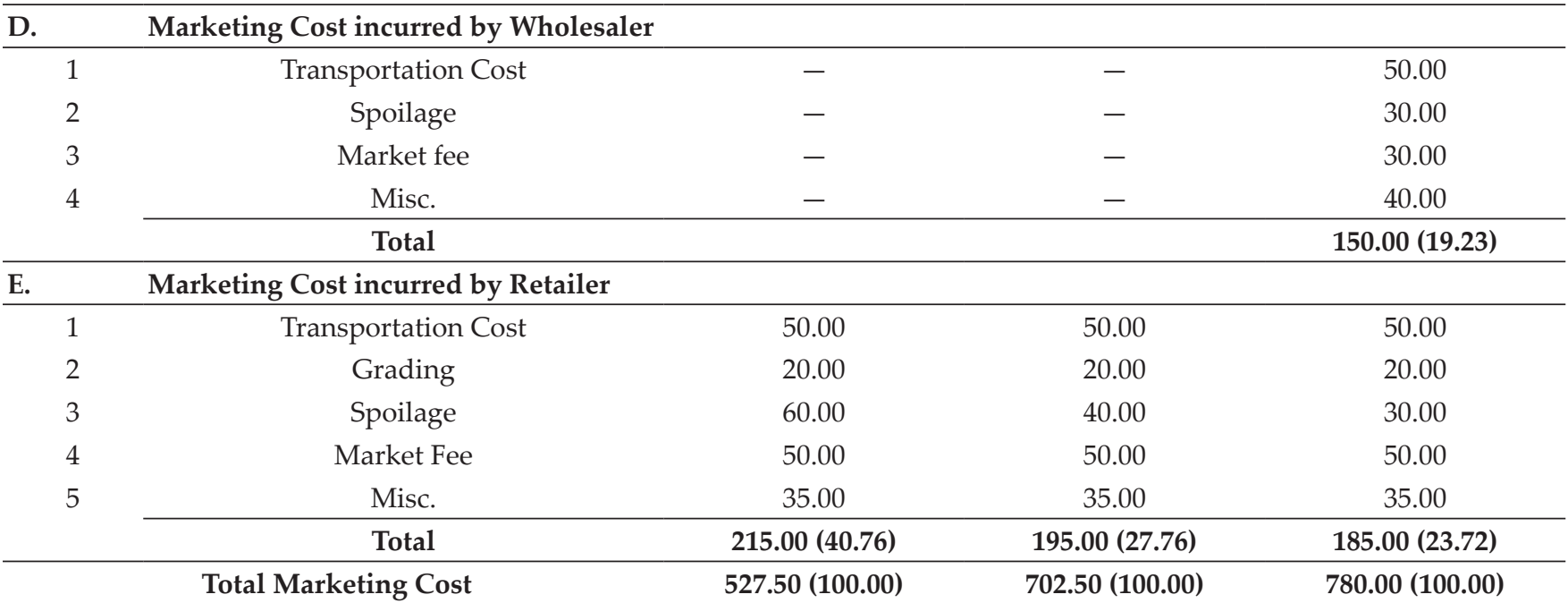

Figures in parentheses are the percentage of total marketing cost.

Source: Primary Survey.

is $40.76 \%$ of the total marketing cost in channel I. The total marketing cost in channel II was ₹ 702.50 per thousand fruits, out of the total marketing cost the marketing cost incurred by merchant wholesaler was ₹ 507.50 per thousand fruits which is $72.24 \%$ of total marketing cost in channel II. Similarly, the marketing cost incurred by the retailer was ₹ 195 per thousand fruits which is $27.76 \%$ of the total marketing cost in channel II. The total marketing cost in channel III was ₹ 780.00 per thousand fruits, out of which the marketing cost incurred by pre harvest contractor was ₹ 445.00 per thousand fruits which is $57.05 \%$ of total marketing cost in channel III. Similarly, the marketing cost incurred 
by the wholesaler was ₹ 150.00 per thousand fruits $(19.23 \%)$ and the marketing cost of retailer was ₹ 185.00 per thousand fruits which is $23.72 \%$ of the total marketing cost in channel III. The total marketing cost incurred in rupees per thousand fruits was highest in channel III (₹ 780.00) followed by channel II (₹ 702.50) and channel I (₹ 527.50).

In the study area, where channel I was followed, marketing was of two types; cooperative marketing and self or solo marketing. In case of cooperative marketing, the produce was assembled from different growers in a village and then the combined produce is taken to the market for sale. Each grower receives payment in accordance to the number of fruits that they contribute. The producers involved in self or solo marketing are usually marginal producers living in close proximity to the market. Even, if they have very less amount of produce like only 500-1000 fruits, they participate in direct sale in the market which fetches them good price as the plucking and transportation is solely undertaken by them, no external person or labour is involved in it. The produce is packed in boxes or bags and carried on motorcycle or any other two wheelers which makes it cheap and efficient.

\section{Marketing margin and Price Spread}

The Table 5 revealed the results related to the marketing margin, price spread and producer's share in consumer's rupee under different marketing channels which revealed that the producer received maximum net price per thousand fruits in Channel I (₹ 2900.00) followed by Channel II (₹ 2200.00) and Channel III (₹ 1300.00). The merchant wholesaler's marketing cost and marketing margin in channelII was ₹ 507.50 per thousand fruits and ₹ 1017.50 per thousand fruits respectively. The retailer's marketing cost and marketing margin in channelII was ₹ 195.00 per thousand fruits and ₹ 2100.00 per thousand fruits, respectively. The pre-harvest contractor's marketing cost and marketing margin in channel III was ₹ 445.00 per thousand fruits and

Table 5: Channel-wise marketing margin, price spread and producer's share in consumer's rupee (Rupees per thousand fruits)

\begin{tabular}{cccc}
\hline Name of the functionary/ Items of Cost & Channel I & Channel II & Channel III \\
\hline Net Price received by producer & 2900.00 & 2200.00 & 1300.00 \\
Cost incurred by producer & $312.50(5.43)$ & - & - \\
Producer's sale price & 3212.50 & 2200.00 & 1300.00 \\
Merchant Wholesaler Purchase Price & - & 2200.00 & - \\
Cost incurred by Merchant wholesaler & - & $507.50(8.43)$ & - \\
Merchant Wholesaler's Margin & - & $1017.50(16.90)$ & - \\
Merchant Wholesaler's sale price & - & 3725.00 & - \\
Pre-harvest Contractors purchase price & - & - & 1300.00 \\
Cost incurred by Pre-harvest Contractors & - & - & $445.00(6.98)$ \\
Pre-harvest Contractor's Margin & - & - & $1400.00(21.94)$ \\
Pre-harvest Contractor's sale price & - & - & 3145.00 \\
Wholesaler's Purchase price & - & - & 3145.00 \\
Cost incurred by Wholesaler & - & - & $150.00(2.35)$ \\
Wholesaler's Margin & - & - & $850.00(13.32)$ \\
Wholesaler's sale price & 3212.50 & 3725.00 & 4145.000 \\
Retailer's Purchase Price & $215.00(3.75)$ & $195.00(3.24)$ & 4145.00 \\
Cost incurred by Retailer & $2322.50(40.39)$ & $2100(34.88)$ & $2050.00(2.9)$ \\
Retailer's Margin & $5750.00(100.00)$ & $6020.00(100.00)$ & $6380.00(100.00)$ \\
Retailer's Sale Price/Consumer's Price & 2537.50 & 3820.00 & 5080.00 \\
Price Spread & $50.43 \%$ & $36.55 \%$ & $20.38 \%$ \\
Producer's Share in consumer's rupee & & &
\end{tabular}

Figures in parentheses are the percentage of retailer's sales price.

Source: Primary Survey. 
₹ 1400.00 per thousand fruits, respectively. The wholesaler's marketing cost and marketing margin in channel III was ₹ 150.00 and ₹ 850.00 per thousand fruits, respectively. The retailer's marketing cost and marketing margin in channel III was ₹ 185.00 and ₹ 2050.00 per thousand fruits, respectively. The table also indicated that price spread was maximum in channel III (₹ 5080.00) followed by channel II (₹ 3820.00) and channel I ( $₹ 2537.50$ ), indicated that direct sale of produce to consumer provided a higher share to producer in consumer's rupee. The producer's share in consumer's rupee is highest in channel I (50.43\%) followed by channel II (36.55\%) and channel I (20.38\%) which indicated that less number of intermediaries in a given channel leads to increase in producer's share in consumer's rupee.

\section{Marketing efficiency}

The results in the Table 6 revealed the marketing efficiency and price spread in different channels under study. The results revealed that using Acharya's method, marketing efficiency was found maximum in channel I (1.02), when the produce was sold directly to consumer with only retailer as sole market functionary. When the produce was sold through more number of intermediaries, the marketing efficiency was lower as it was 0.58 in channel-II and 0.26 in channel-I. Similar, results were found from Shepherd's formula also, where marketing efficiency of channel I was maximum (2.02) followed by channel II (1.58) and channel III (1.26).

Table 6: Marketing efficiency of different channels in the study area

\begin{tabular}{ccccc}
\hline Sl. & Particulars & \multicolumn{3}{c}{ Channels } \\
\cline { 3 - 5 } No. & & I & II & III \\
\hline 1 & $\begin{array}{c}\text { Net price received by } \\
\text { producer (₹) }\end{array}$ & 2900.00 & 2200.00 & 1300.00 \\
& Marketing Cost (₹) & 527.50 & 702.50 & 780.00 \\
2 & Marketing Margin (₹) & 2322.50 & 3117.50 & 4300.00 \\
3 & Price Paid by consumer (₹) & 5750.00 & 6020.00 & 6380.00 \\
4 & Price spread (₹) & 2537.50 & 3820.00 & 5080.00 \\
5 & Marketing efficiency (\%) & 1.02 & 0.58 & 0.26 \\
6 & (Acharya's formula) & & & \\
7 & Marketing efficiency (\%) & 2.02 & 1.58 & 1.26 \\
& (Shepherd's formula) & & & \\
\hline
\end{tabular}

Source: Primary Survey.

\section{CONCLUSION}

From the results, it is concluded that in the study area, only productivity of Khasi mandarin had the positive growth rate (1.08) and both area and production had negative growth rate of $-1.42,-0.36$, respectively. The CV clearly showed that the production had the highest variation followed by area and productivity showed the least fluctuation with their $C V$ value of $8.68,8.05$ and 7.24 , respectively. The marketed surplus was higher in case of medium farms followed by small and marginal farms. The results related to price spread and marketing efficiency revealed that price spread was maximum in channel III (₹ 5080.00) followed by channel II (₹ 3820.00) and channel I (₹ 2537.50), indicated that direct sale of produce to consumer provided a higher share to producer in consumer's rupee and marketing efficiency was found maximum in Channel-I followed by Channel-II and Channel III, through both Acharya's and Shepherd's method. The producer's share in consumer rupee was also found highest in channel I (50.43\%) followed by channel II (36.55\%) and channel I (20.38\%) which indicated that less number of intermediaries in a given channel leads to increase in producer's share in consumer's rupee.

\section{REFERENCES}

Anonymous. 2015. Horticultural Statistics at a Glance 2015. Horticulture Statistics Division, Department of Agriculture, Cooperation \& Farmers Welfare, Ministry of Agriculture, Cooperation \& Farmers Welfare, Government of India, New Delhi.

Anonymous. 2016. Food and Agriculture Organization of the United Nations. FAOSTAT database.

Anonymous. 2016-17b. $2^{\text {nd }}$ advance estimates 2016-17. Ministry of Agriculture and Farmers Welfare, Department of Agriculture, Cooperation \& Farmers Welfare, Government of India, New Delhi.

Anonympus. 2016-17a. Directorate of Horticulture \& Food Processing, Department Of Agriculture \& Horticulture, Government of Assam.

Ray, B.K. and Deka, P.C. 2000. Numerical taxonomic study of different mandarin oranges using morphological characters. Indian Journal of Genetics and Plant Breeding, 60(2): 227-232.

Mahanta, D.K. and Konwar, A. 2014. Production and marketing of orange in Assam -a study on Doomdooma region of Tinsukia district. Journal of Agriculture and Life Sciences, 1(1): 82-90.

Singh, H.P. and Chadha, K.L. 1993. Genetic resources of Citrus. In: Advances in horticulture: Fruit crops -vol. 
1. K.L. Chadha, O.P. Pareek (ed.), Malhotra Publishing House, New Delhi, India, pp. 95-121.

Ghosh, S.P. 1977. Citrus industry of north east India. Punjab Horticultural Journal, 17: 13-21.
Hazarika, T.K. 2012. Citrus genetic diversity of northeast India, their distribution ecogeography and ecobiology. Genetic Resources and Crop Evolution, 59(6): 1267-1280. 
